\title{
Recent Books Delineating the Emergent Academic Filed of the Study of Information ${ }^{\dagger}$
}

\author{
Gordana Dodig-Crnkovic ${ }^{1, *}$ and Mark Burgin ${ }^{2}$ \\ 1 Department of Computer Science and Engineering, Chalmers University of Technology, \\ Gothenburg 40482, Sweden; gordana.dodig-crnkovic@chalmers.se \\ 2 Department of Computer Science, University of California, Los Angeles (UCLA), Los Angeles, \\ CA 90095, USA; markburg@cs.ucla.edu \\ * Correspondence: gordana.dodig-crnkovic@chalmers.se \\ + Conference Theoretical Information Studies (TIS), Berkeley, CA, USA, 2-6 June 2019. \\ Published: 11 May 2020
}

\begin{abstract}
One of the imperative tasks of theoretical information studies is exploration of methods and techniques of presentation of information. In this article, we study the presentation of information in the following three books describing the results of the collaboration of researchers with the goal of defining the emergent filed of the Study of Information: Philosophy and Methodology of Information: The Study of Information in a Transdisciplinary Perspective (2019), Theoretical Information Studies: Information in the World (2020) and Information and Computation (2011), published by World Scientific Publishing Co. Series in Information Studies.
\end{abstract}

Keywords: study of information; information; computation; info-computation; theoretical information studies; methodology of information; transdisciplinarity

\section{Introduction}

An important problem in theoretical information studies is exploration of methods and techniques of presentation of information in general and specific kinds of information such as information about information studies in particular [1]. Here, we consider presentation of information about information, information theory, philosophy and methodology in three recently published books. We analyze the content of these books demonstrating how they help to delineate the emergent filed of the Study of Information and to form the foundations of this field.

\section{Philosophy and Methodology of Information. The Study of Information in the Transdisciplinary Perspective}

Books Philosophy and Methodology of Information [2] and Theoretical Information Studies [3] constitute a duology published to lay out the foundation for the research field of the study of information. Both books are based on the selected materials from the summit of the International Society for the study of information held in Gothenburg in 2017 (http://is4si-2017.org). They represent the basic domains of the study of information-philosophy of information, methodology of information and information theory. The first book contains a collection of the best philosophical and methodological contributions from the Gothenburg summit, with the number of invited contributions of leading researchers in the study of information. The book presents works aimed at establishing philosophical and methodological aspects of a new interdisciplinary/transdisciplinary field of study, with new ways of knowing and novel models of explanation, based on the transdisciplinary approach and data-information-knowledge ecology. It provides perspectives on information as a phenomenon that connects together, and enables new non-reductionist unifications of phenomena usually studied 
in isolation within particular sciences, humanities, technologies and arts, and other information fields. Specialized academic fields currently divide human knowledge and experience into isolated silos. In contrast to this, the study of information creates a holistic approach to the reality defined by the omnipresence and pervasiveness of information in all areas and domains. Founded on the research results of the domain-knowledge, the Study of Information seeks a new, networked, ecological approach to enable an inclusive view, from which future research projects transcending disciplinary boundaries will derive, building on the understanding of information structures and processes underlying particular domains.

This volume emphasizes fundamental dependence of the study of information in general, and the philosophy of information, in particular, on the methodology and logic of information as essential parts of the study of information. It includes works offering new logical perspectives and exploring transconsistent logic for model-based reasoning, arguments for the necessity of logical pluralism, while addressing the logic of transdisciplinarity. In the book, connections of the philosophy of information with sciences and technologies, as well as their societal and ethical aspects within the study of information are explicated. In addition, the authors also make connections with its methodological and logical foundations that are in the process of continuous evolution.

The book consists of four parts: (1) Philosophy of Information, (2) Methodology of Information, (3) Philosophy of the Study of Information, and (4) Methodology of Information Studies.

\section{Theoretical Information Studies. Information in the World}

This second volume [3] in the duology presents the research on establishing theoretical facets of the new interdisciplinary/transdisciplinary field of the study of information, with innovative ways of knowing and advanced models of explanation, established on the forward-thinking general theory of information, data-information-knowledge ecology, reality stratification via levels of abstraction/organization, and information plus computation taxonomies. It provides theoretical perspectives on information and its dynamics including computation and providing a new unification mechanism for phenomena within fields founded on information and computation. Based on the research results of the domain-knowledge, the study of information and computation seeks a new, networked approach to enable an inclusive view, from which future research projects transcending disciplinary boundaries will derive, starting from the understanding of information structures and its processes underlying particular domains. The study of information and computation involves a recursive process of analysis and synthesis through continuous learningabout the natural as well as synthetic/created/cultural worlds, and about their actors-living beings and artificial agents. Theoretical information studies form an essential intrinsic component of the study of information.

Covering the most important domains of theoretical information studies, the book consists of four parts: (1) Foundations of Information, (2) Information as a Natural Phenomenon, (3) Cognition and Intelligence in Natural and Artificial Systems, and (4) Social, Cultural, Ethical and Legal Aspects of Information.

\section{Information and Computation. Essays on Scientific and Philosophical Understanding of Foundations of Information and Computation}

Chronologically, this book [4] preceded the previous two. Thematically, it provides deep-diving into the tandem of fundamental complementary concepts of information and computation, where computation is defined as information dynamics or information process. Information is a basic structure of the world, while computation is a process of the dynamic change of information.

On the one hand, transparent relations between information and computation are explicated in algorithmic information theory [5]. On the other hand, computation is a kind of information processing representing important issues of information dynamics.

Despite increasing importance and omnipresence of information, especially proliferated through Information and Communication Technology (ICT), scientists have not yet come to the common view on the phenomena of information and computation. There are hundreds of approaches 
and dozens of theories but still the concepts of information and computation are evasive and vague, although adequate knowledge about their nature is necessary for our understanding of the world we live in. Understanding the place and role of information in the world is an important philosophical and methodological problem. Some authors relate information only to human communication in society. Others also include information structures and processes on the level of individual human beings. In contrast to this, present authors as well as a number of other researchers working on the naturalization of information, argue that information is everywhere in nature. As a result, researchers study information and its processes (computation) at different levels of the structure of the world. Our approach implies considering the structure of information processes as basic natural, social and technological phenomena. It involves an exploration of relations between the concept of information and basic concepts used to reason about the world, such as matter/energy, mind and knowledge. In this framework, information is related to everything and everything is related to information. For a cognitive agent, epistemologically, energy comes as a kind of information, because for an agent, all physical characteristics are information about the physical world. Theoretically, this is explained in the general theory of information [1]. This understanding is also supported by physicists. For instance, according to Wheeler, exploration of nature demonstrates that every physical quantity derives its meaning from information [6]. Von Weizsäcker developed the fundamental approach to physics based on information, the Ur-theory, with the basic idea that physicists learn about nature through observations, experiments and measurements that enable information extraction from physical objects and processes, as they are entirely characterized by the information that can be acquired from them [7].

Information and Computation provides a cutting-edge view of the world-class authorities in fields where information and computation play a central role. It sketches the contours of the future landscape for the development of our understanding of information and computation, their mutual relationship and the role in cognition, informatics, biology, artificial intelligence, and information technology.

\section{Conclusions}

In this article, we explored information presentation in three books dedicated to the study of information: duology Philosophy and Methodology of Information [2] and Theoretical Information Studies: Information in the World [3] together with the book Information and Computation [4]. They are addressing the study of contemporary dominant and conceptually fundamental dual phenomena of information and computation in a new theoretical, philosophical and methodological framework of knowledge ecology and the general theory of information. These books reflect the work of world's leading researchers within the field, indicating important unsolved problems and opening new directions for the future development.

Funding: The research of the first author is funded by Swedish Research Council grant.

Conflicts of Interest: The authors declare no conflict of interest.

\section{References}

1. Burgin, M. Theory of Information: Fundamentality, Diversity and Unification; World Scientific: New York, NY, USA; London, UK; Singapore, 2010

2. Dodig-Crnkovic, G.; Burgin, M. Philosophy and Methodology of Information. The Study of Information in the Transdisciplinary Perspective; World Scientific: Singapore, 2019. Available online: https://worldscientific.com/ worldscibooks/10.1142/11190 (accessed on 6 May 2020).

3. Burgin, M.; Dodig-Crnkovic, G. Theoretical Information Studies. Information in the World; World Scientific: Singapore, 2020. Available online: https://worldscientific.com/worldscibooks/10.1142/11191 (accessed on 6 May 2020).

4. Dodig-Crnkovic, G.; Burgin, M. Information and Computation; World Scientific: Singapore, 2011. Available online: https://worldscientific.com/worldscibooks/10.1142/7637 (accessed on 6 May 2020).

5. Chaitin, G.J. Algorithmic information theory. IBM J. Res. Dev. 1977, 21, 350-359 
6. Wheeler, J.A. Information, Physics, Quantum: The Search for Links. In Complexity, Entropy, and the Physics of Information; Zurek, W., Ed.; Addison-Wesley: Redwood City, CA, USA, 1990; pp. 3-28

7. von Weizsäcker, C.F. Aufbau der Physik; Hanser, Munich, Germany, 1985; English translation: The Structure of Physics; Springer: Berlin/Heidelberg, Germany; New York, NY, USA, 2006.

(C) 2020 by the authors. Licensee MDPI, Basel, Switzerland. This article is an open access article distributed under the terms and conditions of the Creative Commons Attribution (CC BY) license (http://creativecommons.org/licenses/by/4.0/). 